za de detalhes todos os passos a serem percorridos pelo analista. Completando essa parte, o livro reforça a idéia de que se deve compreender o porquê da descrição do trabalho, principalmente, quando da implantação de um sistema de administração racional do pessoal.

Recrutamentos e seleção assunto obrigatório em qualquer livro sobre recursos humanos é tratado cuidadosamente, de natureza prática e para uso imediato dos empresários. Por extensão, o treinamento é estudado desde a fase preliminar até sua execução $e$ implantação dentro da empresa.

Embora os aspectos mencionados sejam da maior relevância, é na administração de salários que - livro alcança seu ponto máximo. A falta de uma vasta bibliografia não impediu que várias técnicas da administração salarial já utilizadas entre nós fossem analisadas. Pesquisa salarial, avaliação de desempenho, incentivos salariais são tópicos que merecem uma acurada observação, dado - grande potencial de aplicação que o assunto proporciona.

Depois de estudar o instrumental básico do desenvolvimento de recursos humanos - recrutamento, seleção, treinamento e salários - o livro se desdobra nos seguintes tópicos: estruturação de planos de beneficio, estrutura do plano de sugestões, estudos estatísticos da utilização de mão-de-obra, a função do psicólogo e do assistente social, organização e reorganização do setor de recursos humanos, e prevê a atuação da auditoria especificamente no campo objeto do livro.

Comparando o texto da primeira edição com o da segunda edição, encontramos os seguintes pontos de relevância:

1. Avaliação e classificação de cargos. Foi reformulado passando a abranger o estudo de novas experiências com os sistemas de comparação dois a dois e comparação por fatores, e que atualmente vem merecendo a atenção de especialistas das grandes empresas americanas, que os aplicaram e aperfeiçoaram a tal ponto que, de métodos antes condenados e rejeitados, passaram hoje a ser considerados como tão eficazes quanto os métodos tradicionais.
2. Treinamento e formação de recursos humanos. O autor passou a dar maior atenção à instrução programada em sua aplicação empresarial. A instrução programada tem sido considerada como a forma ideal de preparação de mão-de-obra, com extraordinária redução de custos e melhor aproveitamento por parte de alunos-empregados (estagiários). Esse sistema vem sendo utilizado em larga escala em empresas européias e não ganhou, entre nós, o destaque merecido.

3. Administração salarial. Foram incluidos esclarecimentos sobre o sistema interquartilar, com fórmulas de cálculos mais simplificadas do que as anteriores, o que torna mais rápido o cálculo e mais simples a formulação de conclusões das pesquisas salariais. A influência das novas medidas governamentais sobre aumentos sindicais, com a criação do salário normativo e dos aumentos proporcionais, foi analisada e também aplicada às faixas salariais obtidas pelos métodos tradicionais, que, por sua vez, são estudados um a um, com as minúcias de natureza prática.

4. Seleção de pessoal. Foi acrescido um bom número de informaçōes sobre o processamento da seleção de pessoal, divididas em cinco instrumentos de aferição das qualidades dos candidatos.

5. Recrutamento de pessoal. Foram equacionadas as diversas formas de recrutamento, de maneira a permitir ao recrutador segurança ao atuar sobre o mercado de trabalho. E de se ressaltar a maneira pela qual o autor adaptou os conceitos universais à realidade brasileira.

6. O psicólogo e o assistente social. A bibliografia sobre a atuação do psicólogo e do assistente social na administração de recursos humanos ainda não foi devidamente explorada. José Serson foi feliz, pois soube dar conteúdo do trabalho que é desenvolvido por esses profissionais na empreca brasileira.

Luis César G. de Araújo

\section{Sistemas Básicos de Controle de Estoques}

Por Robert Stansbury Stockton. São Paulo, Editora Atlas, 1972. Série Métodos Quantitativos, 139 p. Tradução do original Basic inventory systems, concepts and analysis, 1965, feita pelo prof. Dayr Américo dos Reis.

Após ter dado ao público brasileiro interessado lou de lingua portuguesa) uma série aprofundada de livros sobre compras, administração de materiais e almoxarifado, tais como Administração de materiais de Jorge Sequeira de Araújo, Compras de Stuart Heinritz e o Manual de administração de materiais de Sérgio Messias, a Editora Aitlas lançou o livro em epígrafe como um definitivo avanço em direção a uma maior quantificação dessa ciência de administração de materiais e estoques. De fato, os livros anteriormente existentes em língua portuguesa, como os citados e mais $\mathrm{O}$ método de compras, de England, não eram quantitativos e módernos no sentido da pesquisa operacional e da aplicação da estatística para previsões de estoques e probabilidade para - cálculo de atendimento. Neste pequeno volume, agora, existe um estudo satisfatório e claro que realmente preenche uma lacuna, pois o autor dessa resenha (e seus colegas) do Manual de administração da produção, da Fundação Getulio Vargas, escreveram capitulos de uma obra maior; acontecendo o mesmo com o livro de Maynard traduzido para o portugues. 
O livro de Stockton é moderno, e após definir claramente os conceitos, o que é uma raridade hoje em dia, chega, já no terceiro e quarto capítulos ao, "ponto de pedido" e "lote econômico". A dedução do lote econômico pelo autor parece um pouco anticlimática, pois após um exaustivo estudo das três alternativas de atendimento: a) entrega parcial, b) recepção (entrega) completa e c) preço variável, o autor chega à expressão matemática do custo total. Mas, depois não deduz ou deriva do custo total a fórmula do lote econômico, levado por uma vontade de evitar envolvimento do leitor com cálculo diferencial. Isso, porém, não faz mal, pois os outros livros citados tratam disso. O uso da solução tabular é muito interessante, apesar de que a constante do custo total anual de compra nem sempre precisa ser incluída, só quando há descontos de quantidade. Falta tornar isso bem claro. Os capítulos quinto e sexto são dedicados a sistemas de revisão periódica e suprimentos agregados, respectivamente. Mais uma vez acreditamos que se trata de algo inédito na literatura em português.

A flutuação de pontos de pedido é tratada ainda no quarto capítulo. O trabalho dos professores Zaccareli e Magee, respectivamente da Universidade de São Paulo e da Harvard Business School (na época), também existe em português, mas a reunião de todos os dados no mesmo lugar torna o livro essencialmente valioso. Infelizmente o sétimo capítulo é muito curto, uma vez que maior ênfase em sistemas integrados, que nele são tratados, teria dado um fecho de ouro ao livro.

Resumidamente, trata-se de um ótimo livro para o nível de graduação e pós-graduação em administração de empresas e em eriģenharia de produção, pressupondo um mínimo de cálculo diferencial (para achar máximo e mínimo) e de probabilidade, para achar estoques de reserva e cálculos de atendimento. Três objetivos poderão dar ao livro também utilidade industrial: difundir a teoria do atendimento, aumentar a sensibilidade sobre probabilidade de variação do consumo semanal ou mensal e, finalmente, tornar mais quantitativo o tratamento do problema de estoques industriais.
A tradução do livro está ótima. Há pequenos senões, que mudam - sentido de certas frases; por exemplo, na página $25,3^{a}$ linha do último parágrafo está: "são mais complexos e mais resolúveis", onde provavelmente deve ser menos. Na p. 17 está "complação" em lugar de contração de inventário. Exponencial smoothing foi traduzido como "suavização exponencial" (p. 29, nota 6), em lugar de "nivelamento exponencial", usado por outros autores. Sensitivity-analysis ficou "análise da sensitividade" - palavra que ainda não consta dos dicionários - o que é tão bom quanto "de sensibilidade" do resultado. O livro está sendo usado em seminário de nível pós-graduado, e está satisfazendo, logo, que mais será necessário? E um louvor à Editora Atlas por uma gama completa de livros sobre o assunto, que não concorrem entre si, mas se completam. E obrigado pela bibliografia adicional nacional.

atis

Kurt E. Weil

\section{Administração da Produção}

Por Raymond Richard Mayer. São Paulo, Editora Atlas, 2 v. 740 p. Bibliografia original, 1972. Tradução do original Production management, 1968, feita por Clovis Monteiro e Rubens Valdergoria (USP).

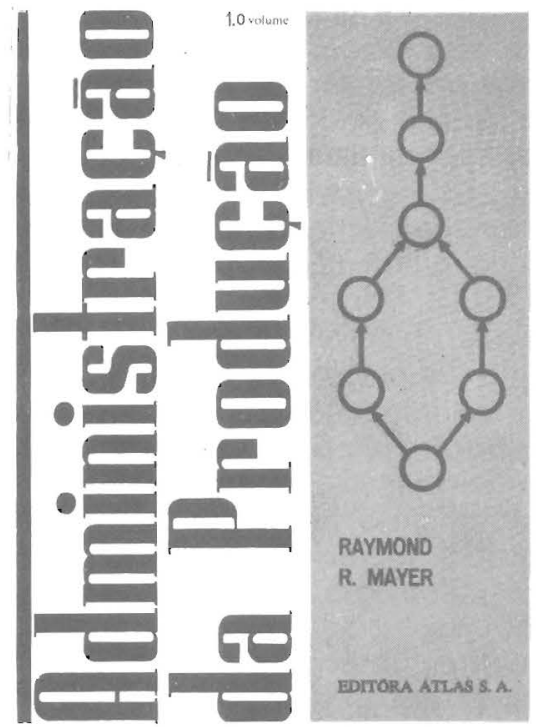

Com este livro finalmente temos uma escolha completa para o ensino da administração da produção - há livros de todas as escolas filosóficas escritos ou traduzidos para o português. Como professor e chefe de departamento, o autor desta resenha costuma deixar livre a escolha do livro mais indicado nos diversos cursos da Fundação Getulio Vargas e o mesmo deve acontecer nas faculdades de administração e engenharia pelo Brasil. É portanto necessário esclarecer a filosofia que deve nortear o ensino e o tipo de livro mais indicado para cada escolha de rumo. Da mesma maneira, na indústria, cada livro tem seu campo específico:

1. O ensino clássico: ponto por ponto se estuda em progressão sistemática o campo da administração da produção. Começa o estudo pela localização de empresas, passa-se pela construção da fábrica, layout, estudos de tempos e métodos, incentivos salariais, controles qualitativo e quantitativo da produção, planejamento da produção, estatística industrial (incluindo a probabilidade no capítulo do controle de qualidade), engenharia econômica, análise de investimentos, pesquisa operacional, incluindo PERT, teoria de fi- 